\title{
VARIABLE MORAINE SPACING ON MOUNT DESERT ISLAND, MAINE - MOUNTAIN BUTTRESSING OF THE ICE FRONT AND/OR REGIONAL SLOWING OF RETREAT DUE TO CLIMATE COOLING?
}

Duane D. Braun, Bloomsburg University of PA geology emeritus and mapping volunteer, Maine Geologic Survey, dbraun9@roadrunner.com

\section{Abstract}

From south to north on Mount Desert Island (MDI) there are about 300 distinct small scale moraine ridges (3-5 $\mathrm{m}$ high, 30-50 $\mathrm{m}$ wide) that occur where the glacier was marine based. Such moraines are lacking or very subdued on the flanks of the northeast-southwest trending mountain range on MDI wherever the elevation is above the $70 \mathrm{~m}$ high stand of sea level. The prominence of thrust features in exposures of such moraines elsewhere in the region indicate they are grounding line or push moraines from annual winter readvance of the ice front across the sea floor.

On the southern part of MDI the push moraines have a somewhat variable spacing of $30-100 \mathrm{~m}$, a spacing intermediate to that of the closely and widely spaced zones to the north. In the center of the MDI at the south ends of the glacial troughs between the mountains there tends to be several much larger moraines with some closely spaced small moraines between them. In the middle of the troughs cut through the mountains the steep slopes retain almost no glacial deposits. Along the north flanks of the mountains and a few $\mathrm{km}$ north of them, the moraine spacing is distinctly closer at $30-60 \mathrm{~m}$. On the northern part of MDI the push moraines have a distinctly wider $100 \mathrm{~m}$ or so spacing. That wide spacing on northern MDI continues north $20 \mathrm{~km}$ to north of Ellsworth.

As indicated by the moraine spacing on $\mathrm{MDI}$, retreat of the ice front slowed when the front reached and was just north of and parallel to the northeast-southwest mountain range. That suggests that the mountain range buttressed the ice front once it moved to the north side of the mountain ranges, thereby slowing the retreat rate. The large moraines $(100+$ volume of material relative to the push moraine) at the south ends of the glacial troughs through the mountains suggests that there was a period of near stability or very slow retreat when the mountains first projected through the ice. Tracing the small push moraines to the northwest across an area without the MDI mountain range to Pineo Ridge though indicates that there is a belt of closely spaced push moraines across the entire region. In the Greenland Ice Sheet Project (GRIP) ice core ${ }^{18} \mathrm{O}$ record, there are dips to more negative ${ }^{18} \mathrm{O}$ values indicative of a colder climate, at $16.1 \pm 0.2$ and $15.7 \pm 0.2 \mathrm{ka}$, times when the ice front should have been at the downeast Maine coast.

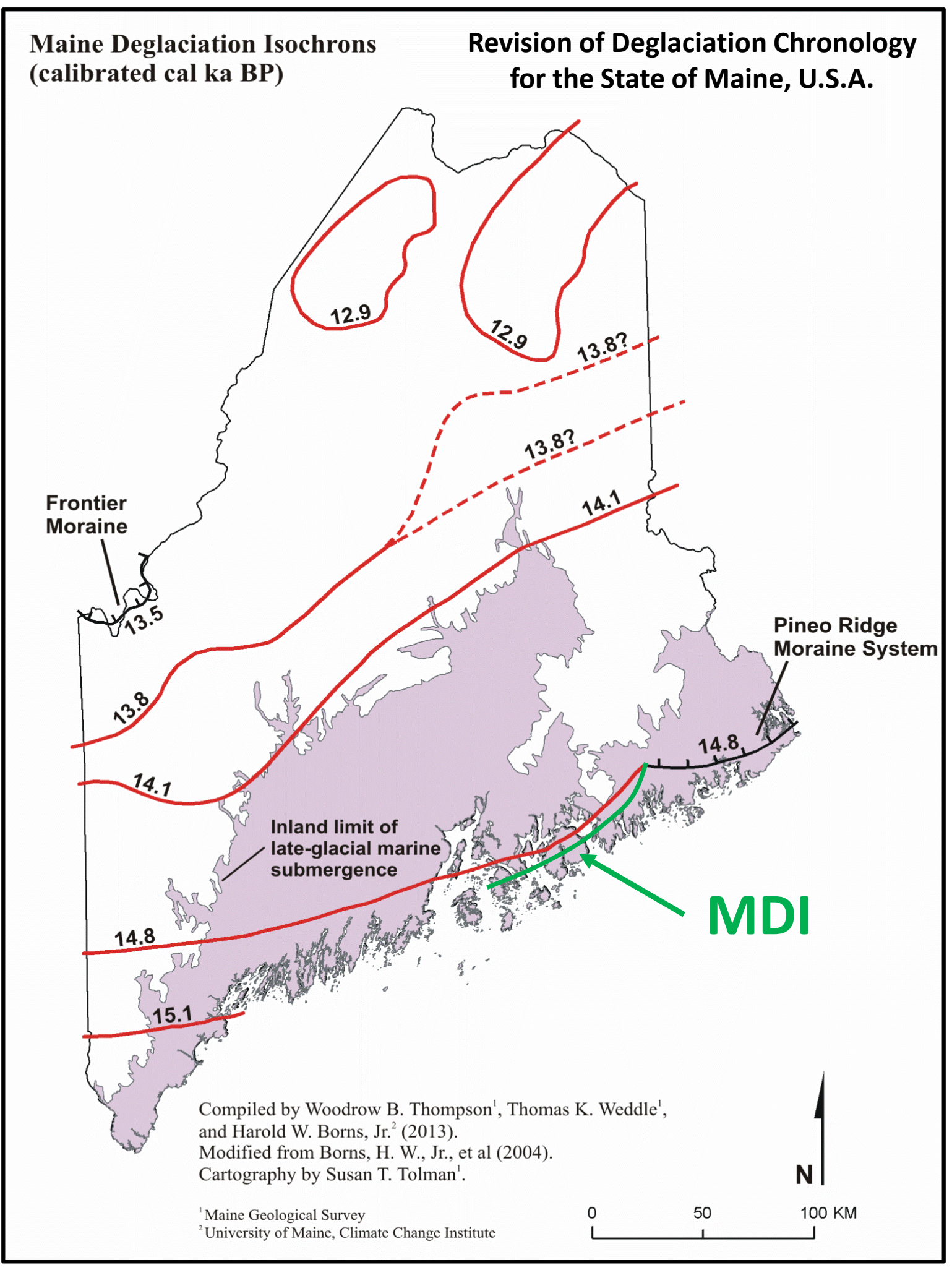

Maine Deglaciation chronology with ages calibrated from $C_{14}$ dates using a 1000 year marine reservoir correction. Using a maximum age calibration produces a $15 \mathrm{ka} B \mathrm{BP}$ age for the Pineo Ridge moraine system. Green line is the $14.8 \mathrm{ka}$ isochron suggested by the correlation of the Pineo Ridge moraine system to MDI moraine system.

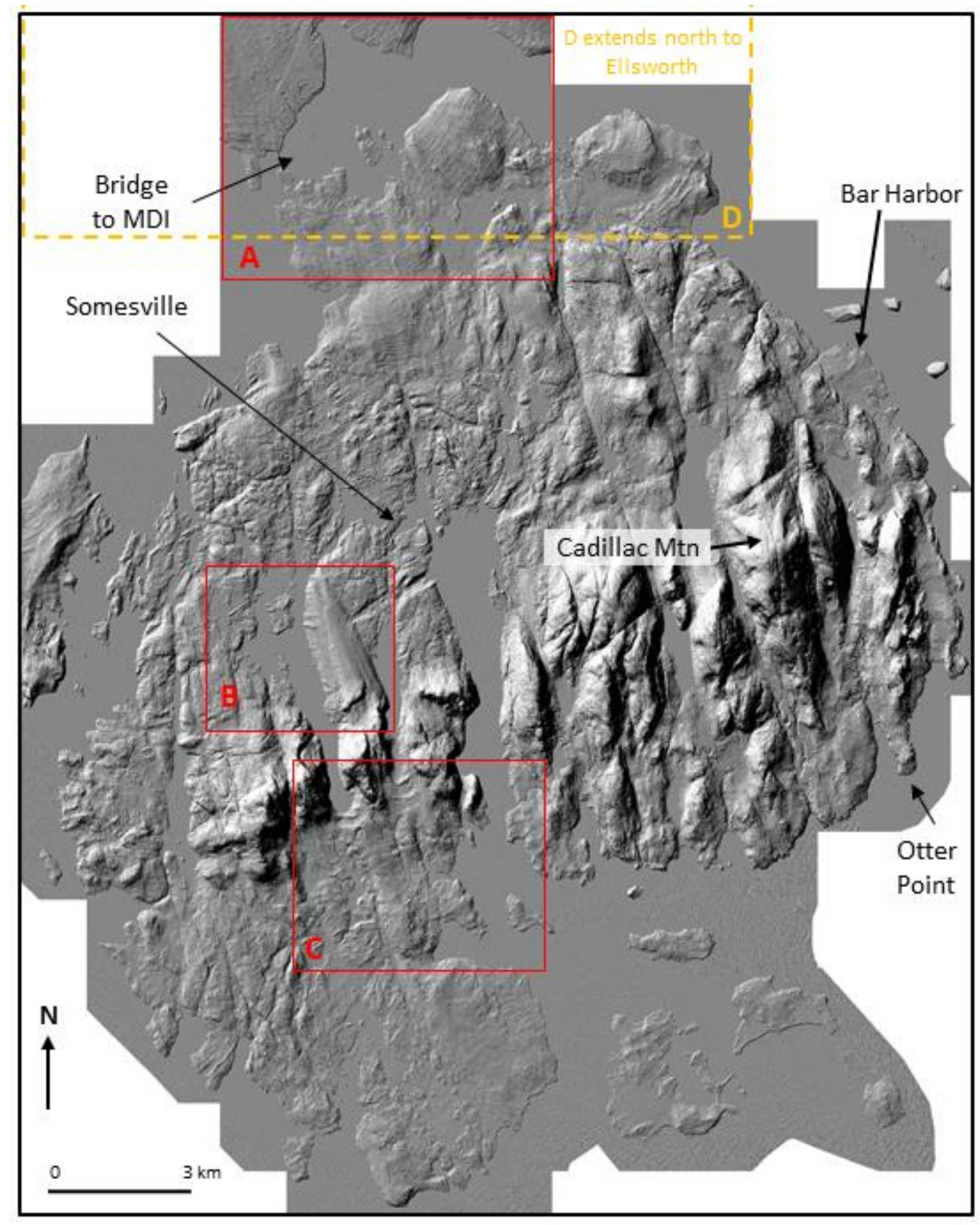

LiDAR image of MDl; even at this scale some of the push moraines are visible. Red rectangles A $-\mathrm{C}$ are enlarged same-scale images shown below for comparison of moraine spacing. Yellow rectangle $D$ is a smaller scale image of the moraine spacing north of MDI shown farther below.

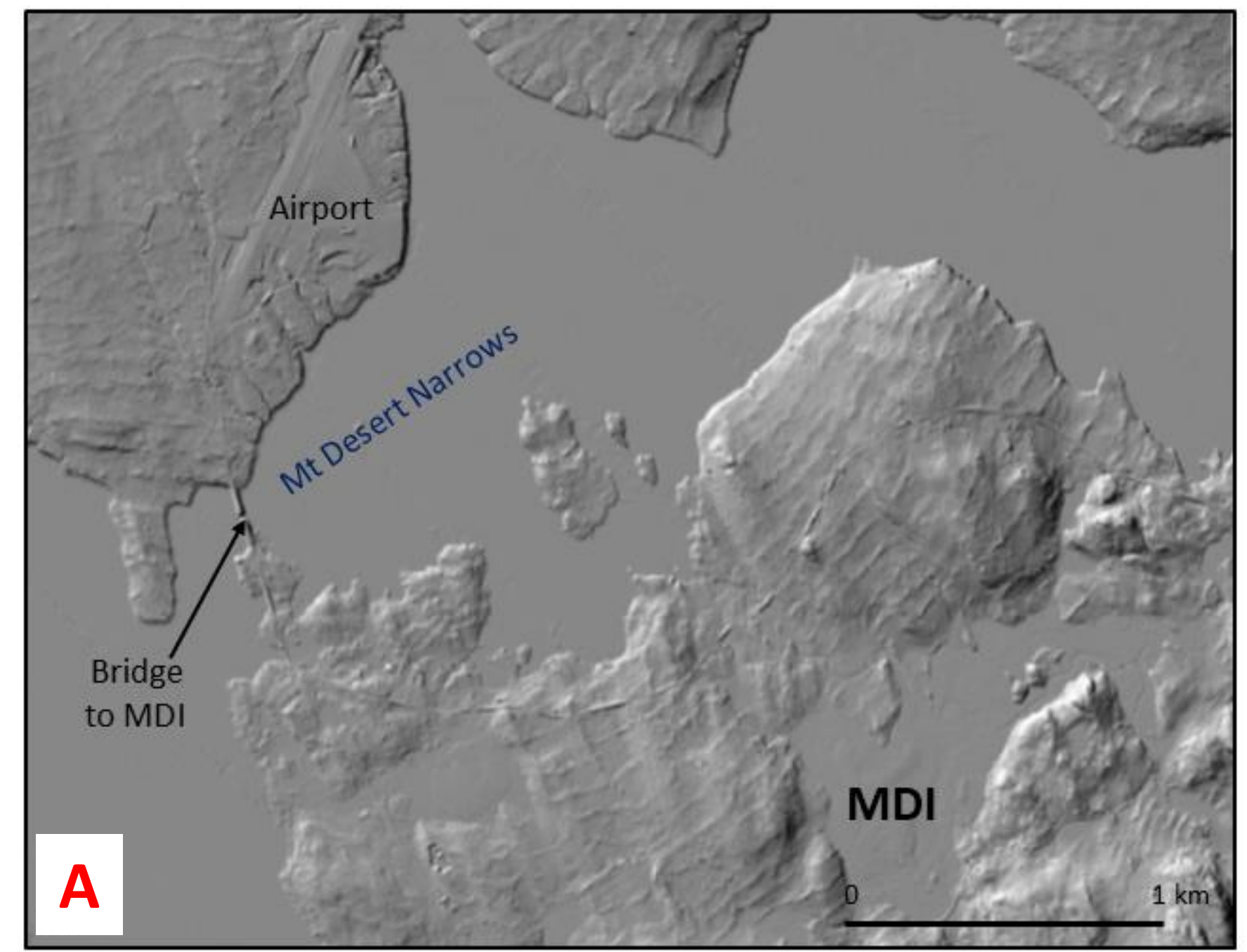

LiDAR close-up of the widely spaced moraines, 100-150 m (330-500 ft) between successive ridges, on the northern part of MDI and on the mainland north of MDI. Same scale as $\mathrm{B}$ and $\mathrm{C}$.

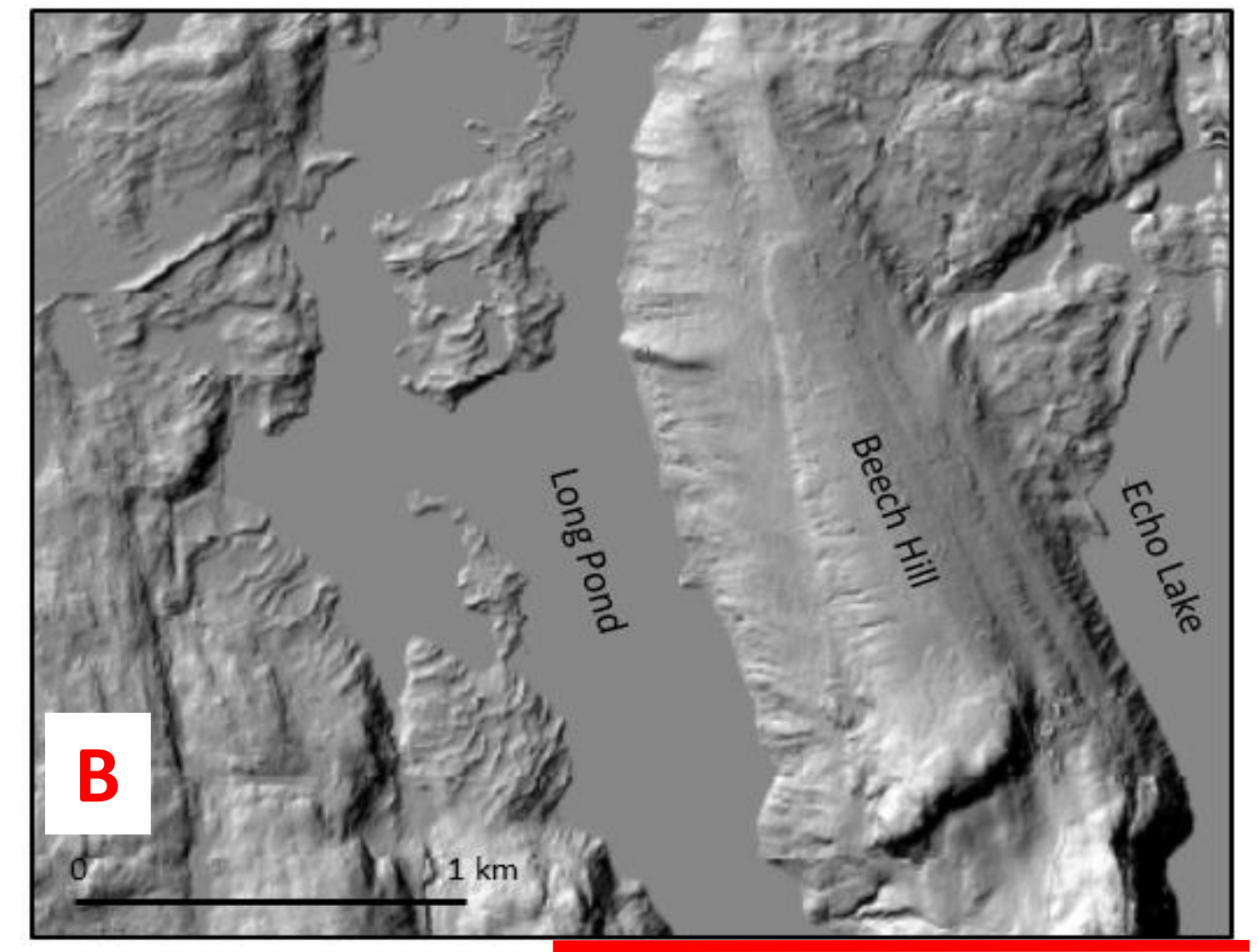

Area that is just north of the northwest corner of the image on the right

LiDAR close-up of the closely spaced moraines 20 $50 \mathrm{~m}(60-165 \mathrm{ft})$ between successive ridges) on the middle part of MDI. The crests of the northeast southwest trending mountain range on MDI are just south of this image and are at the top of the image on the right.

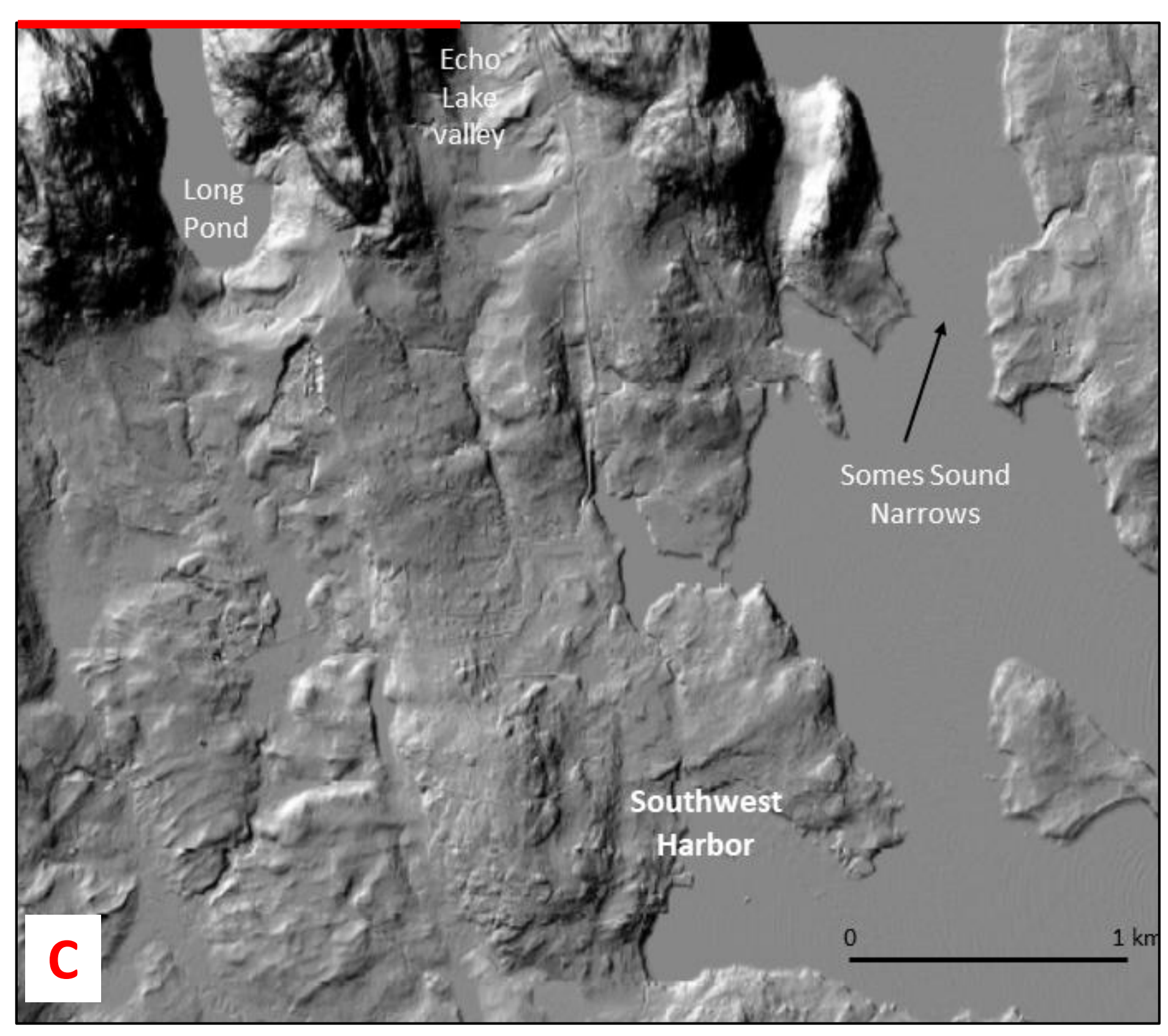

LiDAR close-up of the south ends of the glacial troughs with several much larger moraines. South of there the moraines have a somewhat variable spacing of $30-100 \mathrm{~m}(100-330 \mathrm{ft})$. 
Wider and consistently spaced moraines north of MDI

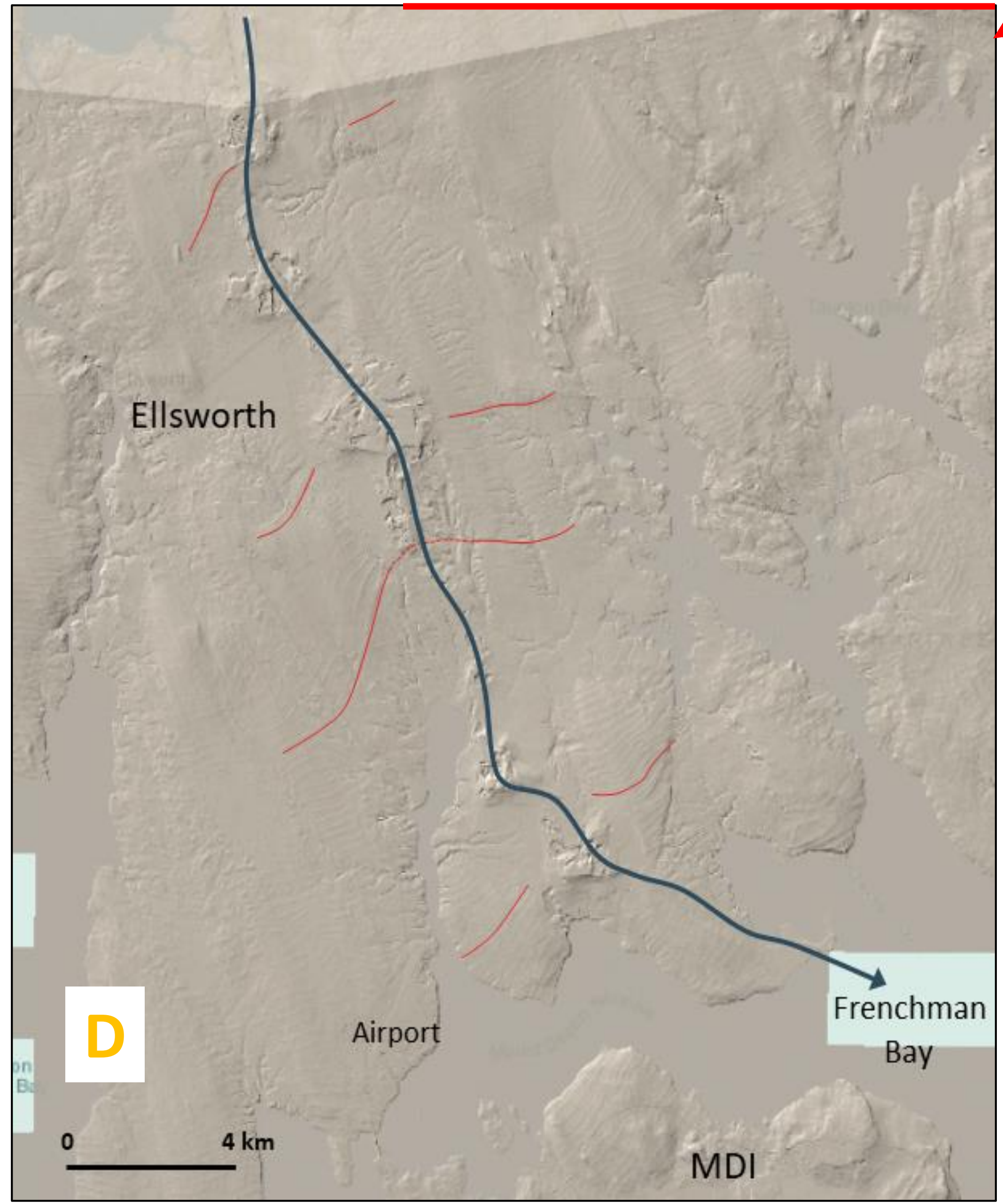

LiDAR image of the small push moraines with a 100-150 m (330-500 ft) spacing from the north side of MDI to north of Ellsworth. Redlines mark the crests of few representative moraines. There are approximately 200 individual moraines in the $30 \mathrm{~km}$ from south to north on the image. The spacing of all the individual moraine crests will be done to correlate these moraines with those to the northeast and southwest of here.

Blue arrow marks the crest of an esker that forms a reentrant in the ice front with the moraines curving northward into it. There are five separate deltas along its trace. The moraine spacing does not change to either side of the deltas indicating the deltas represent pulses of meltwater sediment rather than slowing of the ice front retreat.

Light blue rectangles are places on the water with no LiDAR coverage.


LiDAR image of the small push moraines with a $100-150 \mathrm{~m}(330-500 \mathrm{ft}$ ) or so spacing going northward from the northeast edge of image $D$ on the left. Redlines mark the crests of a few representative moraines. There are approximately 130 individual moraines in the $13.5 \mathrm{~km}$ from south to north on the image. This image is at a somewhat larger scale than the one on the left.

The moraines show a northerly reentrant in the ice front in a shallow valley on the landscape that does not contain an esker.

The northeast corner of the image extends beyond the present LiDAR coverage. 


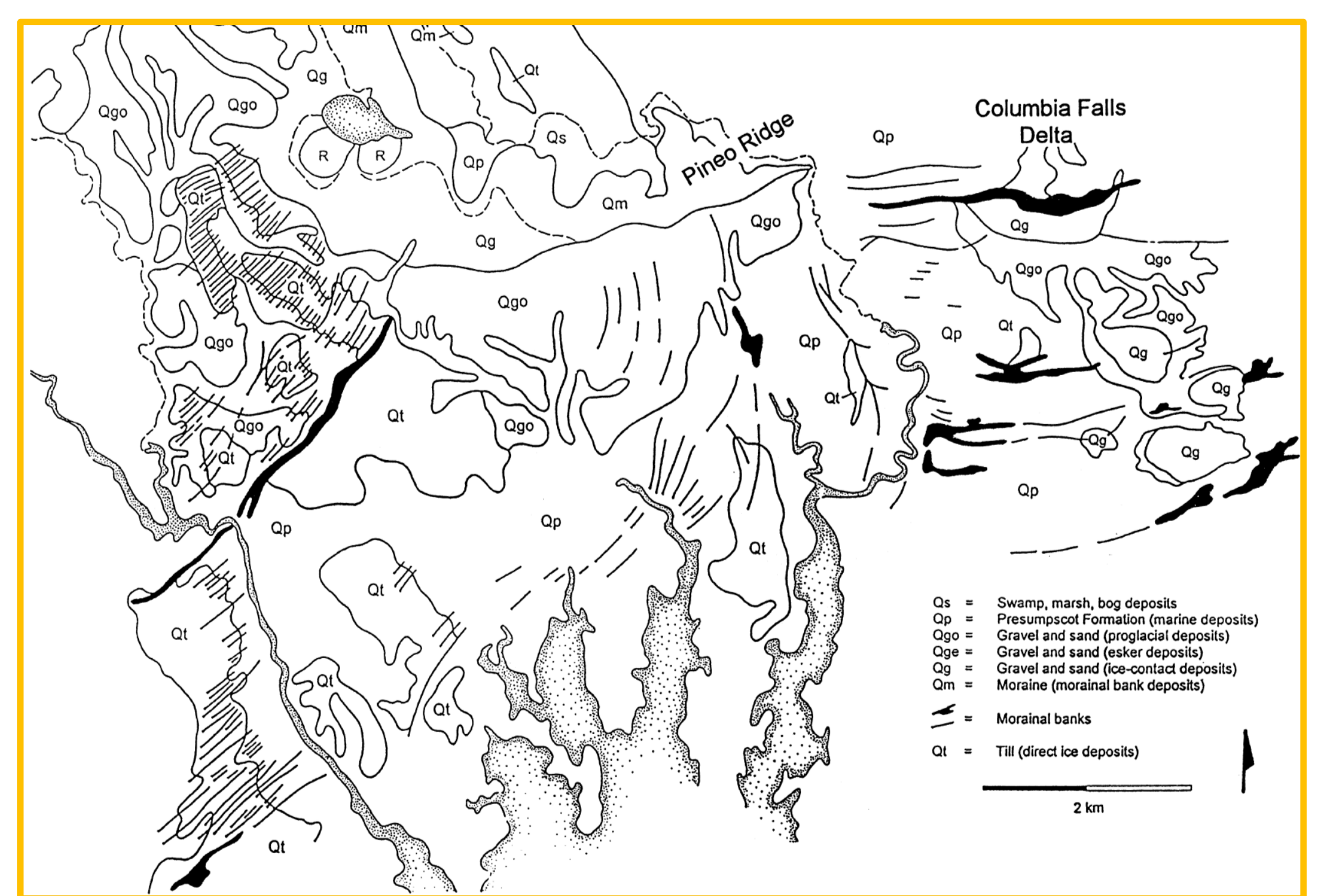

Surficial geology of portion of Cherryfield and Columbia Falls 7.5-minute quadrangles, Maine (Borns, 1975; Borns and Andersen, 1982), showing location of Pineo Ridge and Columbia Falls delta (morainal bank). From Hunter $\&$ Smith, 2001, Morainal banks and the deglaciation of coastal Maine, fig 6.

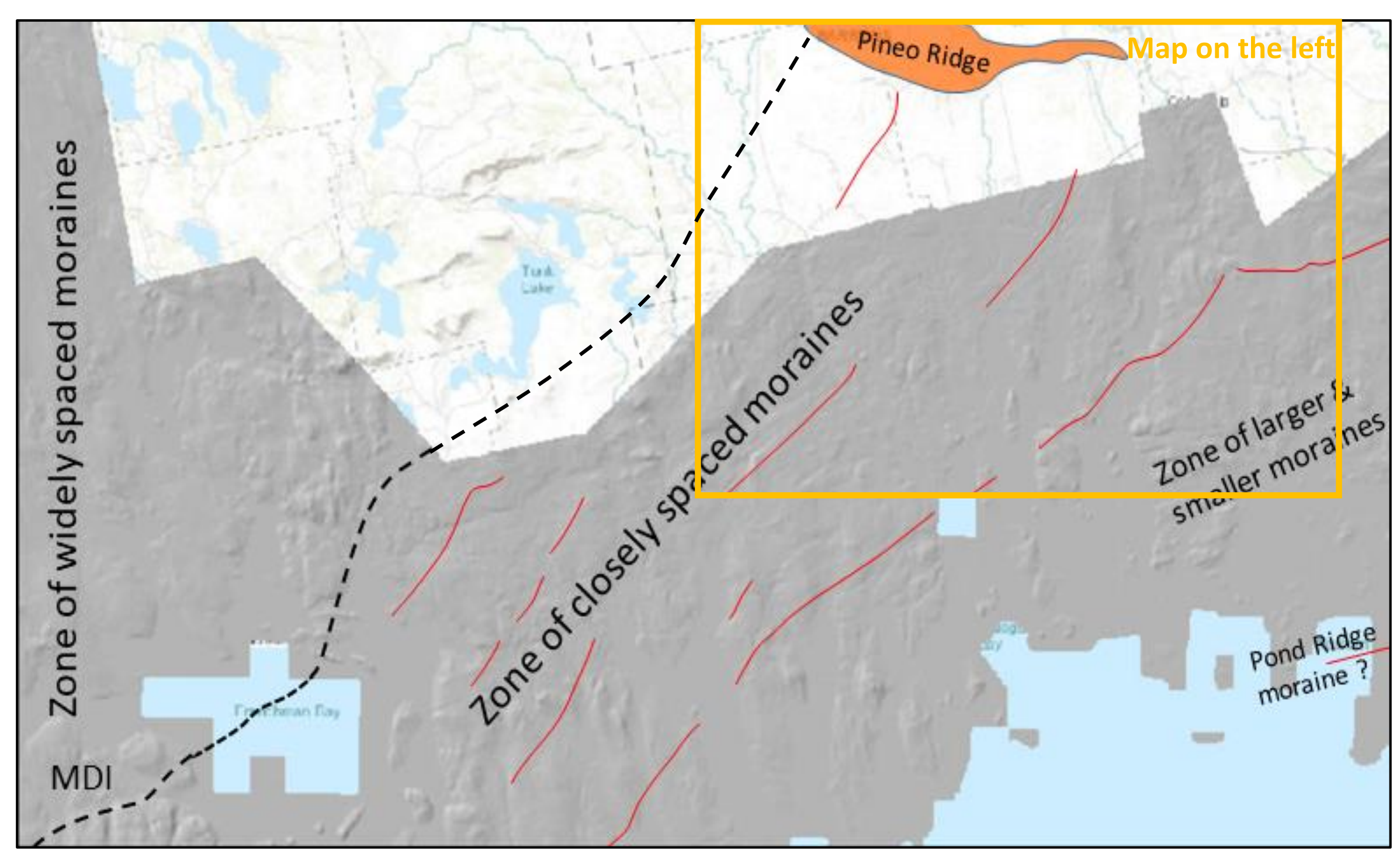

The closely spaced moraine zone extends southwesterly from Pineo Ridge to MDI. Black dashed line marks the northwestern border of the zone while the continuous red line, a larger moraine, marks the southeastern border of the zone. LiDAR coverage as of 2018 is the gray shaded relief area. Revised from Braun, D., 2018, Moraines on MDI and their relation to Pineo Ridge, FOP Guidebook, p. 30, fig. 33.

\section{Closely spaced moraines age match the time of a minor cooling just prior to the start of the Bolling warming episode}

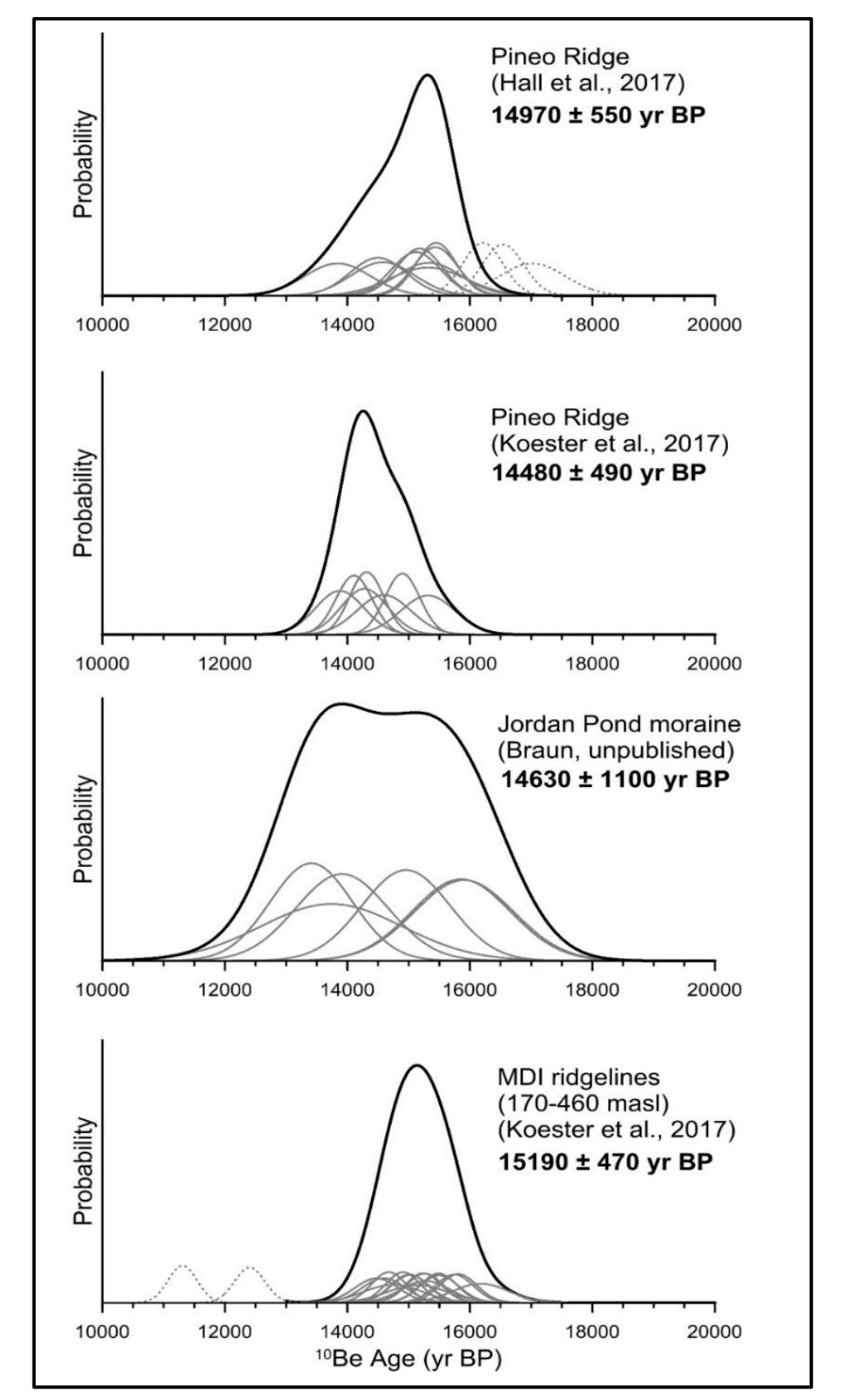

Probability distribution functions (camel plots) of ${ }^{10} \mathrm{Be}$ surface exposure ages from Pineo Ridge and Mount Desert Island, Maine. Mean ${ }^{10} \mathrm{Be}$ surface exposure ages for each grouping labeled in bold, and all four mean ages are indistinguishable at one standard deviation. From Braun, D., 2018, Moraines on MDI and their relation to Pineo Ridge, , fig. 33.FOP 2018 guidebook p. 30

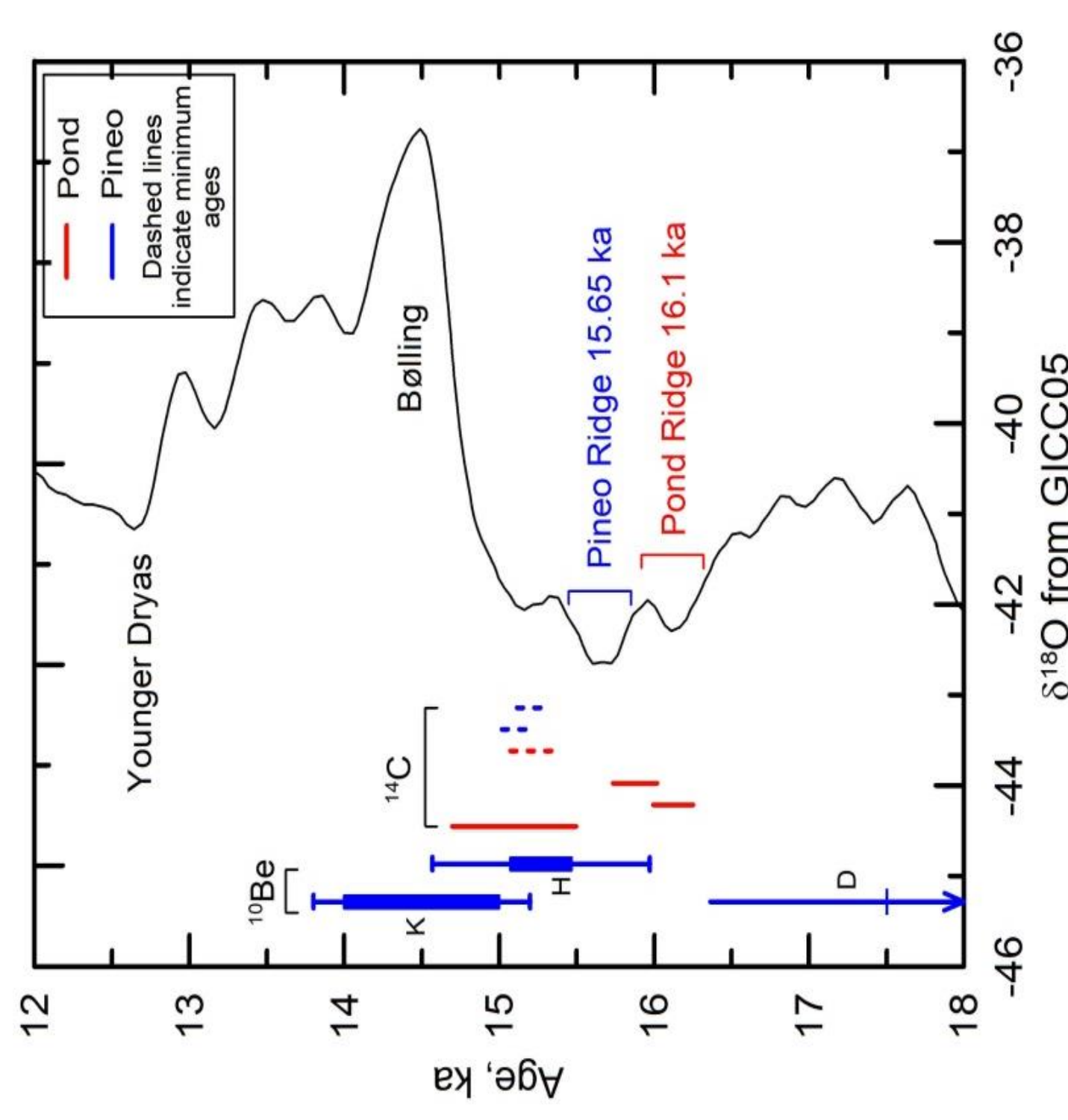

$\mathrm{d}^{18} \mathrm{O}$ record from the GRIP ice core and available dates on the Pond Ridge and Pineo Ridge moraines. Boxes and lines on ${ }^{10} \mathrm{Be}$ dates show internal and external uncertainties, respectively. $\mathrm{K}=$ Koester; $\mathrm{H}=$ Hall; $\mathrm{D}=$ Davis.

From LeB Hooke, R, 2018, How old are the PondRidge and Pineo Ridge morianes?, FOP Guide book, p. 31, fig. 35.

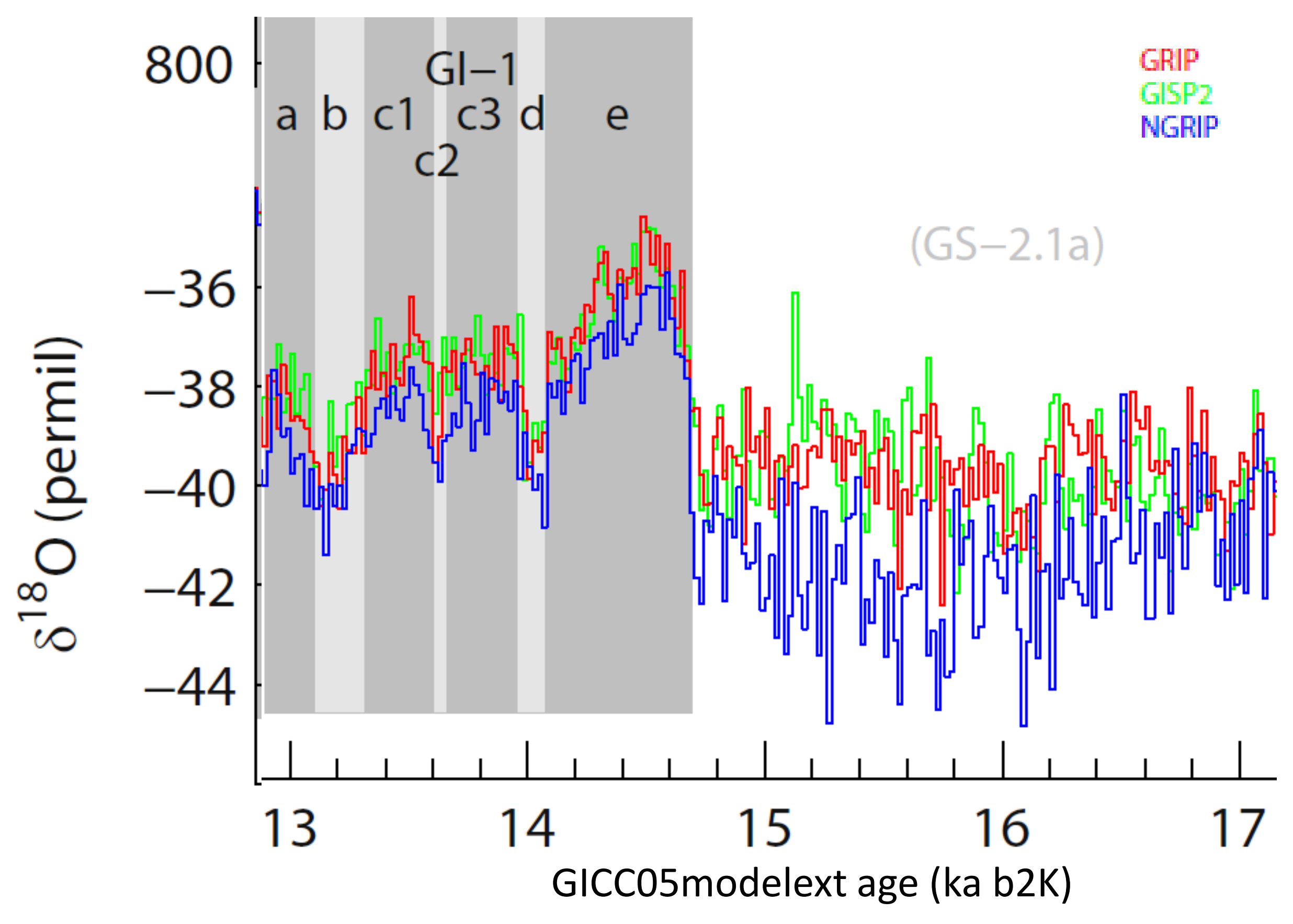

Greenland composite ice-core record showing a minor cooling trend at 2 of the 3 sites, GRIP \& GISP2, in the 14.7-15 ka range. The third site, NGRIP, shows only a distinct short term cooling at around $14.7-14.8 \mathrm{ka}$.

From Rasmussen, S.O., et. al., 2014, A stratigraphic framework for abrupt climatic changes during the last Glacial period based on three synchronized Greenland ice-core records: refining and extending the INTIMATE event stratigraphy, Quaternary Science Reviews, p. 17, fig. 1. 
Greenland ice-core record matched to the Connecticut Valley varve record - a minor readvance from a minor cooling event at $14.7 \mathrm{ka}$

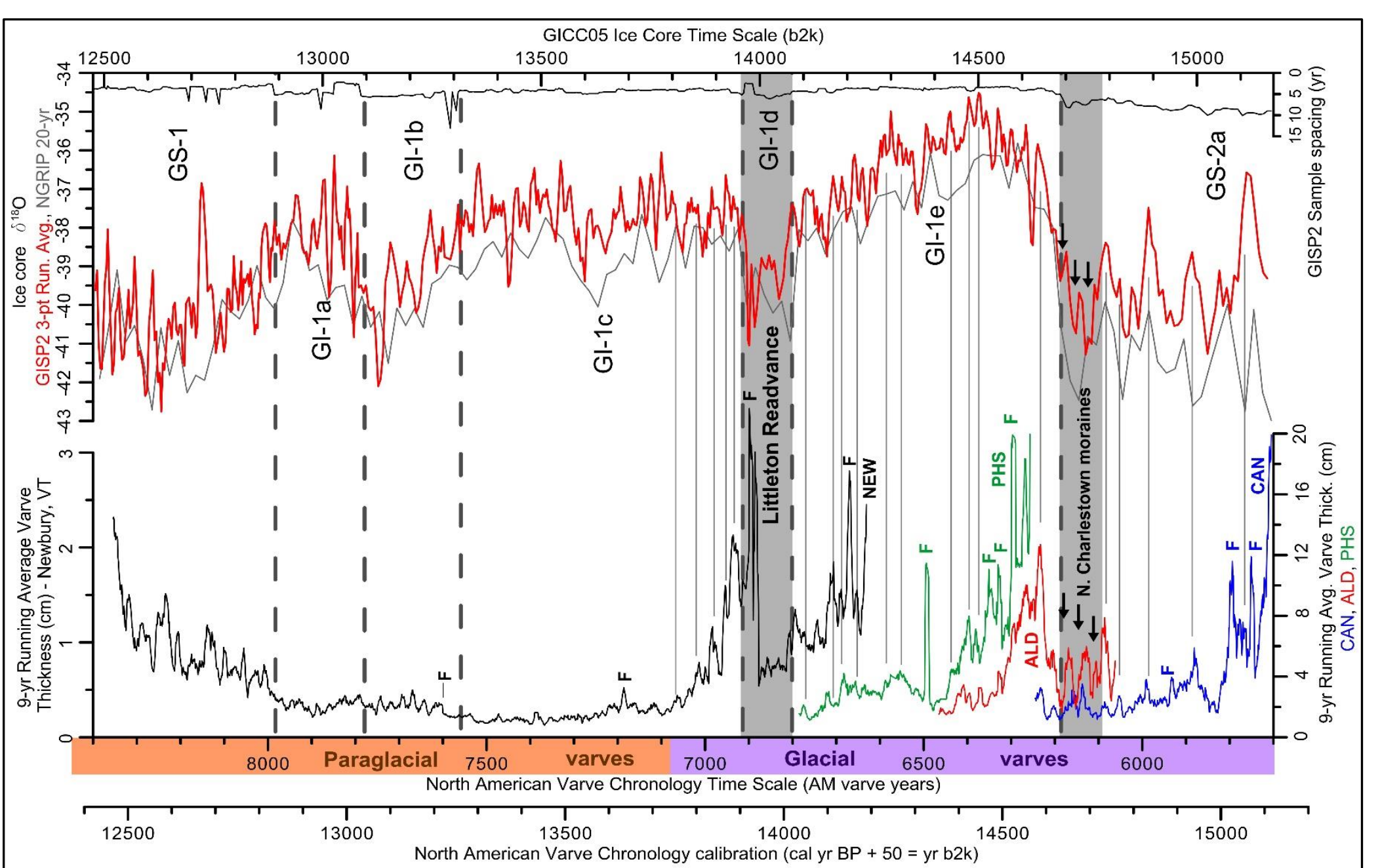

Figure 13 from Ridge, J. et al, 2012, The New North American Varve Chronology: A Precise Record Of Southeastern Laurentide Ice Sheet Deglaciation And Climate, 18.2 $12.5 \mathrm{Kyr} \mathrm{Bp}$, and Correlations With Greenland Ice Core Records, Am J Sci, p. 685-722
Matching the Connecticut Valley retreat record to the Downeast Maine retreat record at $14.7 \mathrm{ka}$

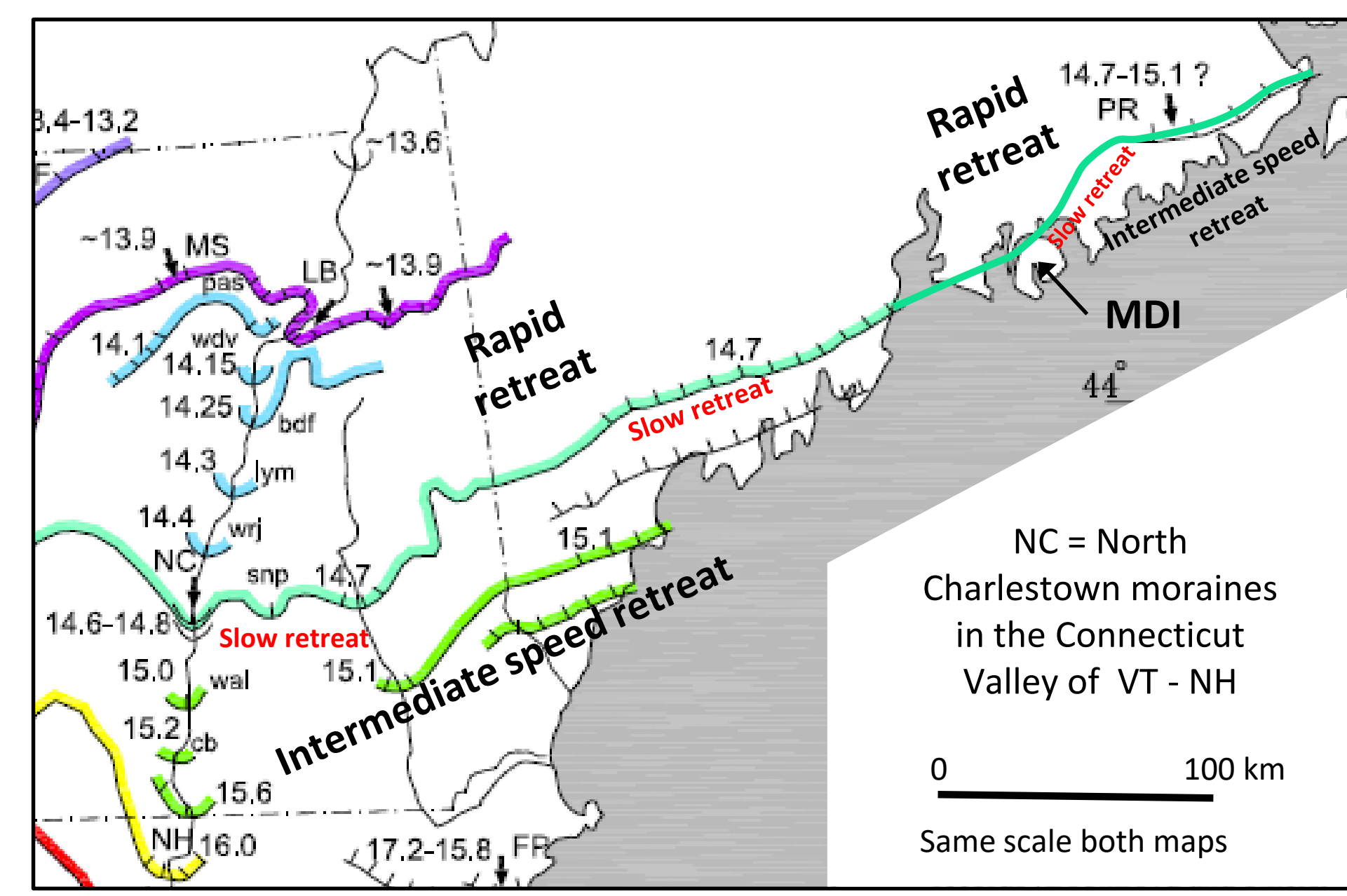

Ice margin map from Ridge (2004) as revised by Ridge 2016, (http://eos.tufts.edu/varves/NAVC/navcdeglac.asp)

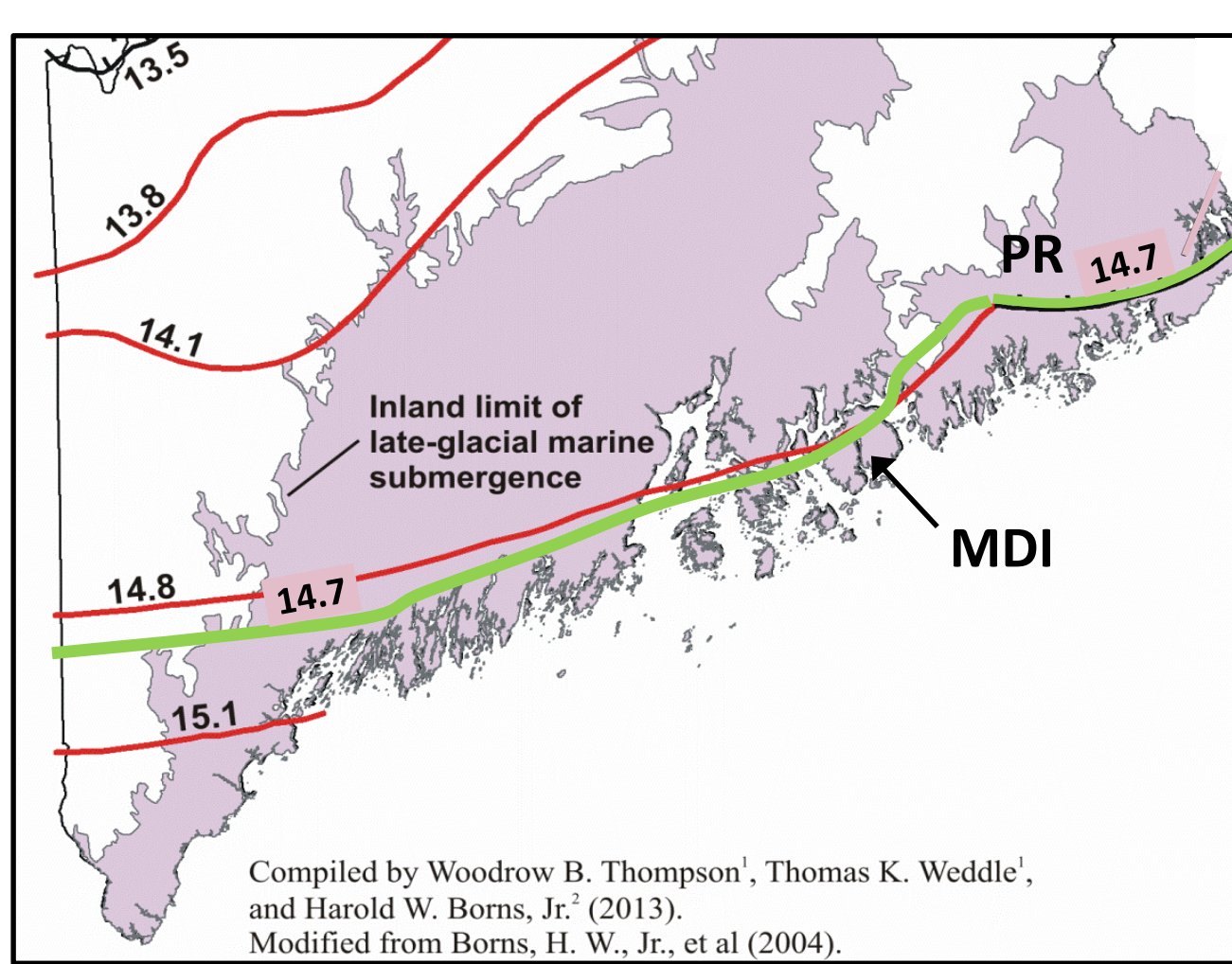

Green line above - Braun's present preliminary projection the MDI - PRS closely spaced moraine belt to the southwest along mid-coast and western Maine using the LiDAR imagery

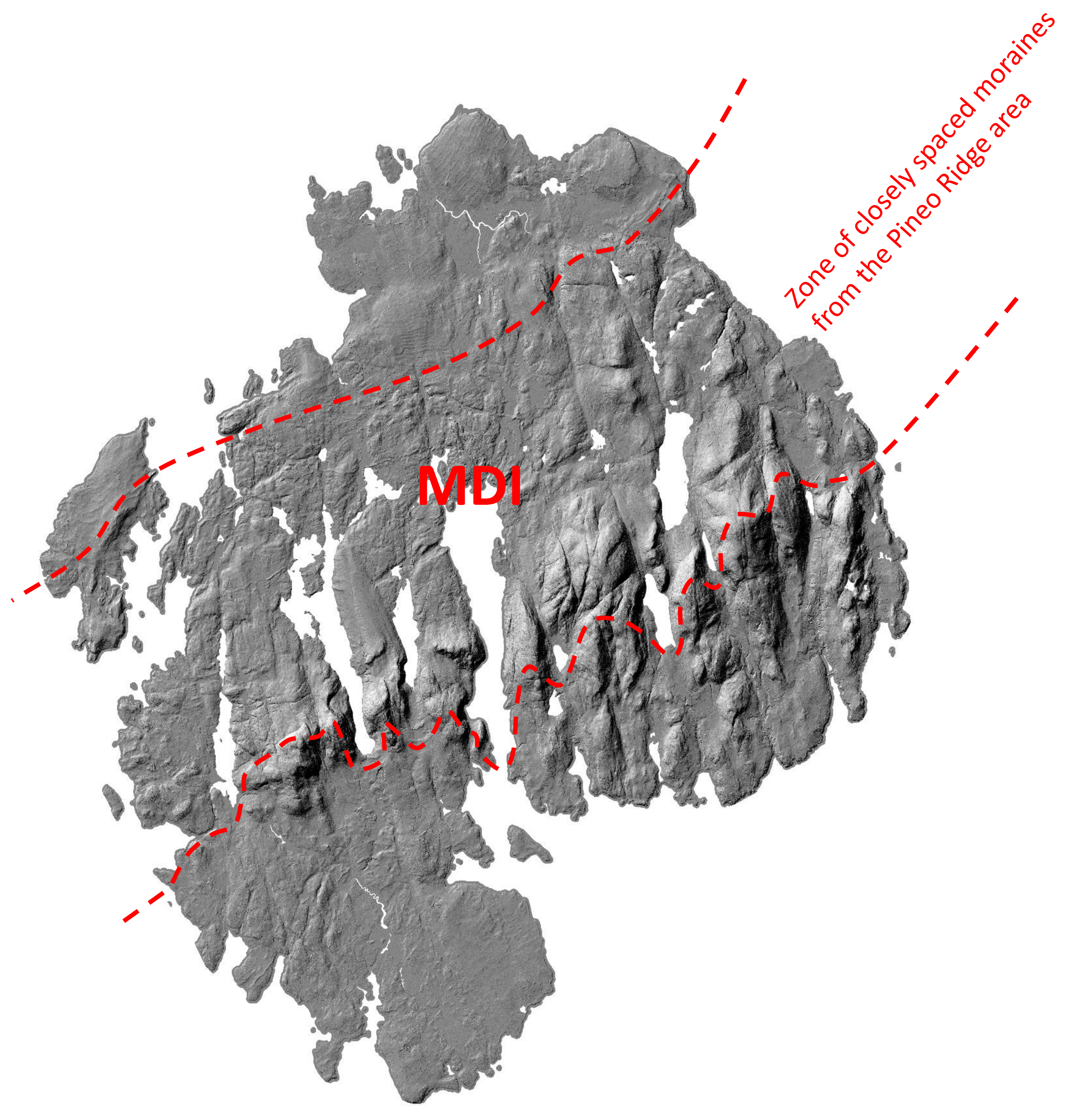

\section{Conclusions}

The image to the left shows that the southern part of the zone of closely spaced moraines coincides with the northern part of the transverse to ice-flow mountain range on MDI. As shown on the graphs above the age of the moraine belt coincides with a minor cooling trend shown in the Greenland ice-core records. Other images to the left of the area north of MDI show that ice retreat was more rapid north of MDI for several hundred years and that coincides with the Bolling warm period. Most likely there is a coincidental combination of buttressing by the MDI transverse to ice-flow mountain range and a minor Laurentide cooling event that produced the very slow retreat of the ice front from the mountains on MDI. 